\title{
PHYSIQUE, BODY COMPOSITION AND PHYSICAL FITNESS OF FINNISH, HUNGARIAN AND AMERICAN ADOLESCENTS
}

\author{
Monika Kaj \\ University of Pecs, Doctoral School of Health Sciences, Pecs, Hungary \\ University of Pecs, Department of Leisure Sports and Recreation, Pecs, Hungary \\ Judit Németh \\ University of Pecs, Doctoral School of Biology, Pecs, Hungary \\ University of Pecs, Department of Leisure Sports and Recreation, Pecs, Hungary \\ Eva Tékus \\ University of Pecs, Doctoral School of Health Sciences, Pecs, Hungary \\ University of Pecs, Department of Sportbiology, Pecs, Hungary \\ Marta Wilhelm* \\ University of Pecs, Department of Leisure Sports and Recreation, Pecs, Hungary
}

\section{Abstract}

The aim of this cross-sectional study was to compare the body structure and physical fitness of Finnish $(n=26)$, Hungarian $(n=42)$ and American $(n=55)$ adolescents $(N=123)$. Height, weight, skinfolds, body fat percentages, circumferences and widths were recorded to define the somatotypological characteristics and growth type of subjects. To define adolescents' healthrelated fitness the Eurofit Fitness Test Battery was used. Differences between the ethnic groups in terms of body composition and motoric performance were analyzed with ANOVA. The prevalence of overweight was $9.3 \%$ among Hungarians, 23.07\% among Finns and 38.2 \% among Americans. PLX is lower $(\mathrm{F}=10.941, \mathrm{P}=0.002)$ in the Hungarian group compared to the Finnish adolescents. Finnish adolescents have higher $\mathrm{VO}_{2} \max$ in both sexes $(34.98 \pm 4.08 ; 41.03 \pm 4.06 \mathrm{ml} / \mathrm{kg} / \mathrm{min})$ despite the fact that they have higher body fat than Hungarians. Comparison between the different ethnic groups suggests that adolescents need higher amount and intensity of training to achieve the proper physical activity level.

Keywords: body composition, physical activity, quality of life, aerobic performance

\footnotetext{
* Corresponding author. University of Pecs, Department of Leisure Sports and Recreation, Ifjusag Street 6, 7624 Pecs, Hungary, e-mail: mwilhelm@gamma.ttk.pte.hu

(C) 2013 Faculty of Sport and Physical Education, University of Novi Sad, Serbia
} 


\section{Introduction}

Obesity in adulthood is an increasing problem worldwide that could be traced back to adiposity and obesity in childhood and adolescence (Saar, 2008). Adiposity in childhood persists in the adolescents, and permanent obesity often leads to many diseases later on like cardiovascular, respiratory, musculoskeletal disorders and a variety of physiological and psychological problems (Marshall, Sarkin, Sallis \& McKenzie, 1998; Tremblay et al., 2011). Obesity will cause disregulation of adipocytokines (TNF- $\alpha$, IL-6, adiponectin) early in life (Nemet et al., 2003). These agents are important in carbohydrate and fat metabolism of fat cells and by this inducing atherosclerosis and type 2 diabetes.

Physical activity in childhood and youth shows a significant correlation with the expected lifetime and life quality, affects lifestyle and physical activity in adulthood (Santtila et al., 2006). Nowadays spontaneous physical activity in childhood is significantly reduced because of certain social expectations and rare and irregular physical activity is constant until adulthood. Prevalence of diseases, which could be prevented with appropriate amount of exercise, is still high in the developed countries (World Health Statistics, 2011).

In the Hungarian population the prevalence of high blood pressure is about $32 \%$ in ages over 15 , the high cholesterol level is more than $12 \%$. More than half of the population above the age of 15 years is overweight, while every fifth person is obese (Maximova, O'Loughlin, Paradis, Hanley \& Lynch, 2009). The normalization of body composition and improvement of physical performance in youth is a very significant social responsibility.

Finland - as other Northern countries - pays close attention to the health of its population foremost not only with rehabilitation. There is a successful health promotion program called North Karelia Project (1972) aiming the reduction of cardiovascular diseases with different methods, including propagation of regular physical activity (McAlister, Puska, Stalonen, Tuomilehto, J. \& Koskela, 1982). For this reason recreational sports play a significant role in the life of this population. Nevertheless according to Kauitainen and collegues (2002) overweight and obesity is increasing in the Finnish adolescent and young population. Age-standardized prevalence of overweight increased in boys from 7.2 to $16.7 \%$, and in girls from 4.0 to $9.8 \%$, between 1977 and 1999, while the percentage of adolescents with lower BMI did not change. According to Ogden and colleagues, $31.7 \%$ of children and adolescents were at or above the $85^{\text {th }}$ percentile of BMI for age in the USA (Ogden, Carroll, Curtin, Lamb, \& Flegal, 2010). The prevalence of overweight and obesity has increased since the early 1980s (Malina, 2007) and a consistent decline was registered in aerobic performance of schoolchildren. In Hungary the National Public Health Program would well-support daily regular exercise also (National Institute for Health Development, 2003), although according to statistical data the population does not show a significant increase of interest related to physical activity (Currie, Hurrelmann, Settertobulte, Smith \& Todd, 2000). The study by Armstrong and Welsman (2006) shows that in the ages from 10 to 15 years greater physical activity pattern is found in almost every European country compared to Hungary.

According to a Hungarian representative study less than $50 \%$ of 11 years old boys and about $35 \%$ of girls met the guidelines criteria of recommended physical activity by WHO ( 5 times a week, at least one hour). At the age of 15 years only $30 \%$ of boys and $20 \%$ of girls were active enough (Currie et al., 2004). Sedentary lifestyle is more often observable by the girls, 58\% of them do exercises, while this value by the boys is $70 \%$. Simultaneously with increasing age the participation in organized sport occupations is reduced in both sexes. This implies the deterioration 
of physical fitness of the youth. A European representative survey has shown that $77 \%$ of the Hungarian population was inactive in 2010 (Eurobarometer, 2010).

Beside lower cardiorespiratory fitness the unfavorable development of body composition could be observed in adolescents also. While the amount of subcutaneous fat is generally increasing, the development of motoric performance is worse than it is expected in the biological development (Photiou et al., 2008).

The guidelines (ICC) of the recommended amount of physical activity were described in 1993. According to ICC, 20 minutes of vigorous exercise is needed 3 times or more in a week besides the varied daily physical activity (Sallis \& Patrick, 1994). The American Physical Therapy Association Section on Pediatrics supports the guidelines as youth should participate in at least 60 minutes physical activity each day to promote overall health and wellness (Ganley et al., 2011). Additional recommendation is strength training two times a week (Sallis \& Patrick, 1994). The numbers of Physical Education lessons in the Hungarian schools (2-3 times a week) do not provide the sufficient intensity and stimuli frequency needed for biological adaptation, even if time spent with exercise was 45 minutes.

The aim of this study was (i) to compare the body structure and physical fitness of Finnish, Hungarian and American adolescents aged 10 to 14 years, and (ii) to analyze the changes in physique and fitness status in relation to age.

\section{Method}

\section{Participants}

This cross-sectional study was performed with a total of 123 adolescents in Finland ( $n=26)$, Hungary $(n=42)$ and New York State, USA $(n=55) .51 .8 \%$ of the subjects were male and $41.2 \%$ female. The sample selection was non-random based on voluntary registration with parental consent, and all subjects were informed about this study. Data were collected in the year of 2011. This study was performed in accordance with the Declaration of Helsinki and the Research Ethics Committee of the University of Pécs.

Mean age of the sample was $12.31 \pm 1.23$ yrs (BMI: $19.51 \pm 4.47 \mathrm{~kg} / \mathrm{m}^{2}$ ), and it was divided into 3 groups according to ethnic identity: Hungarian group (GH), Finnish group (GF), and American group (GA). The numbers of physical education sessions in schools were 3 for the Hungarian and American adolescents and 2 for the Finnish participants. For GH and GA had possibilities to engage in organized sport activities in the schools as well.

\section{Method of data collection}

All anthropometric measures were carried out by the same investigator. Height was measured with a portable stadiometer to nearest millimeter. Weight was measured using Beurer type electronic scale (Beurer BG 56, Germany), to the nearest $0.1 \mathrm{~kg}$. Body mass index (BMI) was computed as $\mathrm{kg} / \mathrm{m}^{2}$ and overweight and obesity were defined considering the international cut-off points for children (Cole, Belizzi, Flegal, \& Dietz, 2000).

Seven skinfolds (biceps, triceps, subscapular, suprailiac, abdomen, calf and pectoral) were measured on the dominant side. Bodyfat was computed from seven skinfolds according to Durnin and Rahaman (1967), Slaughter et al. (1988) and Brook's (1971) methods. Finally the average bodyfat was calculated of all these values. For skinfold thickness measurements Lange Caliper was used and the measurements were applied on the dominant side of the body. 
Furthermore circumferences (arm, forearm, hand, calf) and width (shoulder, chest, elbow, knee) were recorded to define the subjects' somatotypological characteristics based on HeathCarter modified somatotype method (1967) and growth type based on Conrad method (1963).

The Eurofit Fitness Test Battery (EUROFIT European Tests of Physical Fitness, 1993) was used to evaluate the physical fitness of the subjects including cardiopulmonary fitness, motor and musculoskeletal system fitness: Flamingo-test (general balance), plate tapping (speed of limb movement), sit and reach (lower back flexibility), standing broad jump (explosive strength), hand grip (static strength), sit ups in 30 seconds (trunk strength, abdominal muscular endurance), bent arm hang (functional armstrength), $10 \times 5$ meters shuttle run test (running speed, coordination ability) and finally the 20 meters shuttle run test (cardiorespiratory endurance). This test has been found to be a valid predictor of $\mathrm{VO}_{2}$ max in children and adolescents (van Mechelen, Hlobil \& Kemper, 1986; Boreham, Paliczka \& Nichols, 1990).

It was not possible to perform each Eurofit-tests of American subjects because of the lack of time and facilities (summer camp), for that reason only sit-up, handgrip strength, flexibility, bent arm hanging and standing broad jump tests were completed in that group.

\section{Statistical Analysis}

All data analyses were performed in IBM SPSS Statistics 19.0 statistical program. The Kolmogorov-Smirnov test was used to assess normal distribution of the variables. The standard tests for normality and homogeneity of variance found that these assumptions were valid. Differences between the three ethnic groups in terms of body composition and motoric performance were analyzed with one-way analysis of variance (ANOVA), posthoc tests were calculated with the Bonferroni method. By the variables not having data in GA, independent $t$-test was used.

Data are reported as means \pm standard deviation. P values less than or equal to 0.05 on twosided tests were considered statistically significant.

\section{Results}

\section{Anthropometrical data}

When ethnic groups were included in the analysis as a whole study group age was not different within the groups $(\mathrm{F}=1.075, \mathrm{p}=0.344)$. Several significant anthropometric differences were found between the studied groups. Anthropometric data and body composition of adolescents grouped by ethnic identity are summarized in Table 1. 
Table 1

Anthropometric characteristics of adolescents according to ethnic identity. Data were analyzed with a one-way ANOVA test. Note: * Significant difference $(p<0.05)$ within ethnic groups.

\section{GIRLS}

\begin{tabular}{|c|c|c|c|c|c|}
\hline Variable & $\begin{array}{l}\text { Hungarian } \\
\qquad(n=21)\end{array}$ & $\begin{array}{c}\text { Finnish } \\
(n=15)\end{array}$ & $\begin{array}{c}\text { American } \\
(n=19)\end{array}$ & $\mathbf{F}$ & $\mathbf{P}$ \\
\hline Age & $12.08 \pm 1.36$ & $12.20 \pm 1.15$ & $12.34 \pm 0.52$ & 0.315 & 0.731 \\
\hline Height (cm) & $156.95 \pm 10.44$ & $156.53 \pm 10.40$ & $153.41 \pm 15.20$ & 0.615 & 0.543 \\
\hline Weight (kg) & $43.52 \pm 8.64$ & $50.70 \pm 17.14$ & $49.49 \pm 10.45$ & 2.263 & 0.112 \\
\hline Skinfold at biceps (mm) & $8.46 \pm 2.74$ & $14.02 \pm 5.87$ & $10.56 \pm 3.84$ & 7.563 & $0.002 *$ \\
\hline Skinfold at triceps (mm) & $15.23 \pm 3.96$ & $17.68 \pm 5.74$ & $11.44 \pm 6.72$ & 4.036 & $0.025^{*}$ \\
\hline $\begin{array}{l}\text { Subscapular skinfold } \\
(\mathrm{mm})\end{array}$ & $8.77 \pm 2.71$ & $14.61 \pm 7.19$ & $12.23 \pm 5.86$ & 9.984 & $0.001 *$ \\
\hline $\begin{array}{l}\text { Suprailiacar skinfold } \\
(\mathrm{mm})\end{array}$ & $9.55 \pm 3.75$ & $14.90 \pm 6.69$ & $29.44 \pm 9.91$ & 30.962 & $0.001 *$ \\
\hline Sum of Skinfolds (mm) & $42.01 \pm 11.61$ & $61.20 \pm 24.52$ & $67.78 \pm 22.05$ & 7.679 & $0.001 *$ \\
\hline Body Mass Index $\left(\mathrm{kg} / \mathrm{m}^{2}\right)$ & $17.51 \pm 2.04$ & $20.26 \pm 4.62$ & $21.11 \pm 3.23$ & 8.194 & $0.001 *$ \\
\hline Body fat percentage $(\%)$ & $23.50 \pm 4.39$ & $28.85 \pm 6.77$ & $28.74 \pm 7.09$ & 4.596 & $0.016^{*}$ \\
\hline \multicolumn{6}{|c|}{ BOYS } \\
\hline Variable & $\begin{array}{l}\text { Hungarian } \\
\qquad(n=23)\end{array}$ & $\begin{array}{l}\text { Finnish } \\
(n=12)\end{array}$ & $\begin{array}{c}\text { American } \\
(\mathrm{n}=33)\end{array}$ & $\mathbf{F}$ & $\mathbf{P}$ \\
\hline Age & $12.14 \pm 1.25$ & $12.55 \pm 1.21$ & $12.48 \pm 1.36$ & 0.596 & 0.554 \\
\hline Height (cm) & $163.57 \pm 12.74$ & $156.16 \pm 9.92$ & $150.98 \pm 16.99$ & 5.089 & $0.008^{*}$ \\
\hline Weight (kg) & $51.55 \pm 16.12$ & $46.95 \pm 8.87$ & $47.87 \pm 14.73$ & 0.584 & 0.560 \\
\hline Skinfold at biceps (mm) & $7.39 \pm 3.95$ & $11.41 \pm 4.54$ & $7.54 \pm 3.00$ & 5.504 & $0.006^{*}$ \\
\hline Skinfold at triceps (mm) & $12.68 \pm 4.95$ & $14.64 \pm 4.73$ & $7.86 \pm 5.29$ & 10.442 & $0.001 *$ \\
\hline $\begin{array}{l}\text { Subscapular skinfold } \\
(\mathrm{mm})\end{array}$ & $9.47 \pm 4.78$ & $11.79 \pm 3.69$ & $12.56 \pm 5.97$ & 2.325 & 0.106 \\
\hline $\begin{array}{l}\text { Suprailiacar skinfold } \\
(\mathrm{mm})\end{array}$ & $9.51 \pm 6.19$ & $12.60 \pm 5.43$ & $21.36 \pm 12.79$ & 10.068 & $0.001 *$ \\
\hline Sum of Skinfolds (mm) & $39.06 \pm 19.07$ & $50.44 \pm 17.35$ & $49.29 \pm 24.39$ & 1.739 & 0.184 \\
\hline Body Mass Index $\left(\mathrm{kg} / \mathrm{m}^{2}\right)$ & $18.82 \pm 3.37$ & $19.12 \pm 2.19$ & $20.85 \pm 4.93$ & 1.972 & 0.146 \\
\hline Body fat percentage $(\%)$ & $20.99 \pm 5.89$ & $24.95 \pm 4.33$ & $22.64 \pm 6.25$ & 1.692 & 0.192 \\
\hline
\end{tabular}


The average height of boys was $154.85 \pm 16.02 \mathrm{~cm}$ and $155.03 \pm 13.01 \mathrm{~cm}$ of girls. There was no difference between the three groups (GA, GH, GF) in BMI of the boys $\left(20.02 \pm 0.2 \mathrm{~kg} / \mathrm{m}^{2}\right)$, while among girls GF $\left(20.25 \pm 4.62 \mathrm{~kg} / \mathrm{m}^{2}\right)$ and GA $\left(21.12 \pm 3.23 \mathrm{~kg} / \mathrm{m}^{2}\right)$ have significantly greater BMI than GH $\left(17.51 \pm 2.04 \mathrm{~kg} / \mathrm{m}^{2}, \mathrm{p}<0.05\right)$.

Differences in skinfolds after post-hoc tests are shown in Figure 1. The average skinfold thickness was generally higher in GF, as was the sum of four skinfolds suggesting adolescents in GF have larger subcutaneous fat deposits. Consequently the body fat content is higher in GF and GA in both sexes compared to GH. This body fat difference is significant between girls in GF and $\mathrm{GH}(\mathrm{p}=0.028)$.

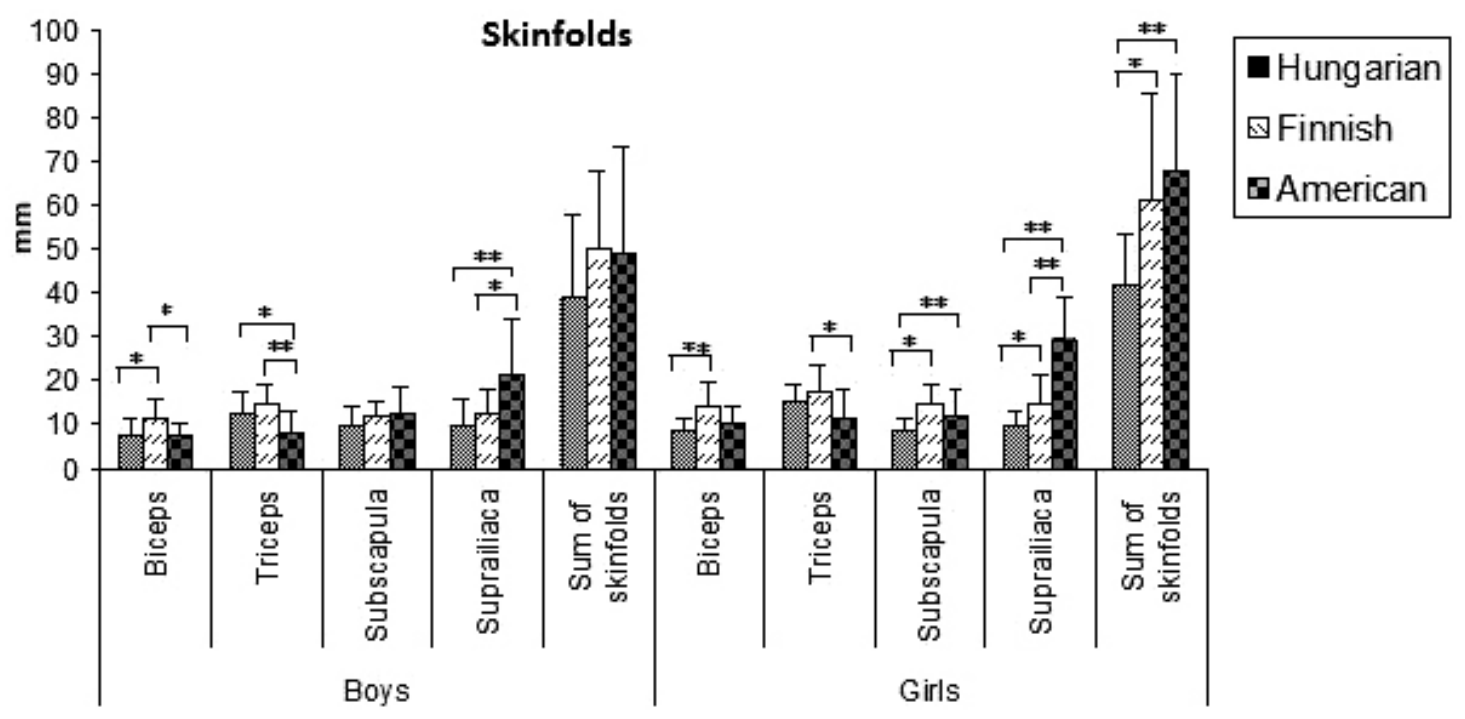

Figure 1. Significant differences (one-way ANOVA, see Table 1.) in skinfolds according to ethnic identity. Asterisks $\left({ }^{*} \mathrm{p}<0.05,{ }^{* *} \mathrm{p}<0.001\right)$ indicate results of post-hoc test (Bonferroni).

Average PLX value of GH in girls is $73.30 \pm 4.77$, and $80.22 \pm 4.75$ in GF ( $F=10.941$, $\mathrm{P}=0.002$ ). MIX of the studied adolescent girls in $\mathrm{GH}$ is $-2.84 \pm 0.41$, that significantly differs from GF $(-2.32 \pm 0.72 ; \mathrm{F}=6.705, \mathrm{P}=0.014))$. Male subjects in $\mathrm{GH}$ have PLX value of $79.23 \pm 7.08$ and $-0.78 \pm 0.58$ of MIX value, and it is significantly lower than it was found in GF $(-0.29 \pm 0.47$; $\mathrm{F}=5.604, \mathrm{P}=0.025)$ ).

In girls' data of the Heath-Carter components are 3.93-4.66-3.13 in GH, 5.14-6.09-2.26 in GF and 6.01-6.63-1.76 in GA. These average values in boys are 3.66-5.66-2.97 in GH, 4.456.68-2.49 in GF and 4.59-5.03-1.86 in GA.

\section{Physical fitness}

The results of Plate Tapping test and Flexibility test were significantly better in girls in each groups (Table 2), while boys performed in every other motor tests better than girls $(\mathrm{p}<0.05)$. Significant difference between the three ethnic groups was only achieved with the Flexibility test in boys. Adolescents in GF showed $19.77 \pm 5.6 \mathrm{~cm}$ average value differing significantly from GA $(13.45 \pm 3.12 \mathrm{~cm})$ and subjects in $\mathrm{GH}$ reached $17.71 \pm 4.78$ value in this test. 
Table 2

Results of Eurofit tests of adolescent ages 10 to 14 according to ethnic identity. Data were analyzed with a one-way ANOVA. Note: * Significant difference $(p<0.05)$ within ethnic groups.

\section{GIRLS}

\begin{tabular}{|c|c|c|c|c|c|}
\hline Variable & $\begin{array}{c}\text { Hungarian } \\
(n=21)\end{array}$ & Finnish $(n=15)$ & $\begin{array}{c}\text { American } \\
(n=19)\end{array}$ & $\mathbf{F}$ & $\mathbf{P}$ \\
\hline $\begin{array}{l}\text { Flamingo (number } \\
\text { of fails) }\end{array}$ & $2.29 \pm 0.92$ & $2.13 \pm 0.35$ & - & 0.383 & 0.540 \\
\hline Plate Tapping (s) & $11.42 \pm 1.33$ & $13.35 \pm 2.77$ & $14.13 \pm 2.32$ & 7.714 & $0.009 *$ \\
\hline Handgrip test (kg) & $16.92 \pm 4.89$ & $26.92 \pm 8.56$ & $25.04 \pm 6.49$ & 12.795 & $0.001^{*}$ \\
\hline $\begin{array}{l}\text { Standing Broad } \\
\text { Jump }(\mathrm{cm})\end{array}$ & $169.07 \pm 20.74$ & $141.4 \pm 21.81$ & $140 \pm 19.86$ & 12.688 & $0.001 *$ \\
\hline Sit-up & $24.09 \pm 4.60$ & $15.33 \pm 2.31$ & $17.46 \pm 7.15$ & 12.212 & $0.001 *$ \\
\hline $\begin{array}{l}\text { Flexibility test } \\
(\mathrm{cm})\end{array}$ & $26.50 \pm 7.91$ & $21.58 \pm 4.68$ & $22.14 \pm 3.96$ & 4.626 & $0.039 *$ \\
\hline $\begin{array}{l}\text { Bent arm hanging } \\
\text { test }(\mathrm{s})\end{array}$ & $12.24 \pm 10.36$ & $11.45 \pm 11.41$ & $7.43 \pm 5.29$ & 0.821 & 0.447 \\
\hline $\begin{array}{l}\text { 20m shuttle run } \\
\text { test (VO2max, } \mathrm{ml} / \\
\mathrm{kg} / \mathrm{min})\end{array}$ & $31.46 \pm 4.93$ & $34.98 \pm 4.08$ & - & 5.134 & $0.030^{*}$ \\
\hline
\end{tabular}

\section{BOYS}

\begin{tabular}{lccccc}
\hline Variable & $\begin{array}{c}\text { Hungarian } \\
(\mathbf{n = 2 3})\end{array}$ & Finnish (n=12) & $\begin{array}{c}\text { American } \\
(\mathbf{n}=\mathbf{3 3})\end{array}$ & $\mathbf{F}$ & $\mathbf{P}$ \\
\hline $\begin{array}{l}\text { Flamingo (number } \\
\text { of fails) }\end{array}$ & $2.63 \pm 1.13$ & $2.73 \pm 1.19$ & - & 0.046 & 0.832 \\
Plate Tapping (s) & $11.66 \pm 2.26$ & $12.53 \pm 1.67$ & $12.73 \pm 2.09$ & 1.218 & 0.306 \\
Handgrip test (kg) & $26.12 \pm 10.57$ & $31.62 \pm 9.33$ & $27.08 \pm 9.47$ & 1.227 & 0.299 \\
$\begin{array}{l}\text { Standing Broad } \\
\text { Jump (cm) }\end{array}$ & $194.09 \pm 43.27$ & $182.36 \pm 19.89$ & $176.87 \pm 31.28$ & 1.395 & 0.257 \\
Sit-up & $24.50 \pm 4.37$ & $22.18 \pm 4.64$ & $22.25 \pm 4.41$ & 1.986 & 0.145 \\
$\begin{array}{l}\text { Flexibility test } \\
\text { (cm) }\end{array}$ & $17.71 \pm 4.78$ & $19.77 \pm 5.61$ & $13.45 \pm 3.11$ & 8.565 & $0.001 *$ \\
$\begin{array}{l}\text { Bent arm hanging } \\
\text { test (s) }\end{array}$ & $22.60 \pm 19.42$ & $16.43 \pm 8.24$ & $18.69 \pm 14.58$ & 0.663 & 0.519 \\
$\begin{array}{l}\text { 20m shuttle run } \\
\text { test (VO2max, ml/ }\end{array}$ & $36.89 \pm 8.66$ & $41.03 \pm 4.06$ & - & 2.218 & 0.147 \\
$\mathrm{~kg} /$ min) & & & & & \\
\hline
\end{tabular}


In girls the average of Handgrip strength test was $16.93 \pm 4.89 \mathrm{~kg}$ in $\mathrm{GH}, 26.92 \pm 8.59 \mathrm{~kg}$ in GF, and $25.04 \pm 6.49 \mathrm{~kg}$ in GA, the differences were significant ( $\mathrm{p}=0.001$, Table2, Fig2). The Hungarian girls' performance was the best in terms of the Plate Tapping, Standing Broad Jump, Sit-up and Bent Arm Hanging test (Figure 2).

The average maximal oxygen uptake achieved with the $20 \mathrm{~m}$ shuttle run test is $31.46 \pm 4.93$ $\mathrm{ml} / \mathrm{kg} / \mathrm{min}$ by the female subjects in GH significantly differing from GF, where the average value was $34.99 \pm 4.08 \mathrm{ml} / \mathrm{kg} / \mathrm{min}$ ( $\mathrm{p}=0.030$, Table 2$)$. However the difference of $\mathrm{VO}_{2}$ max is nonsignificant in males, the average value is higher in the Finnish group ( $41.03 \pm 4.06 \mathrm{ml} / \mathrm{kg} / \mathrm{min})$ compared to the Hungarian boys $(36.89 \pm 8.66 \mathrm{ml} / \mathrm{kg} / \mathrm{min})$.
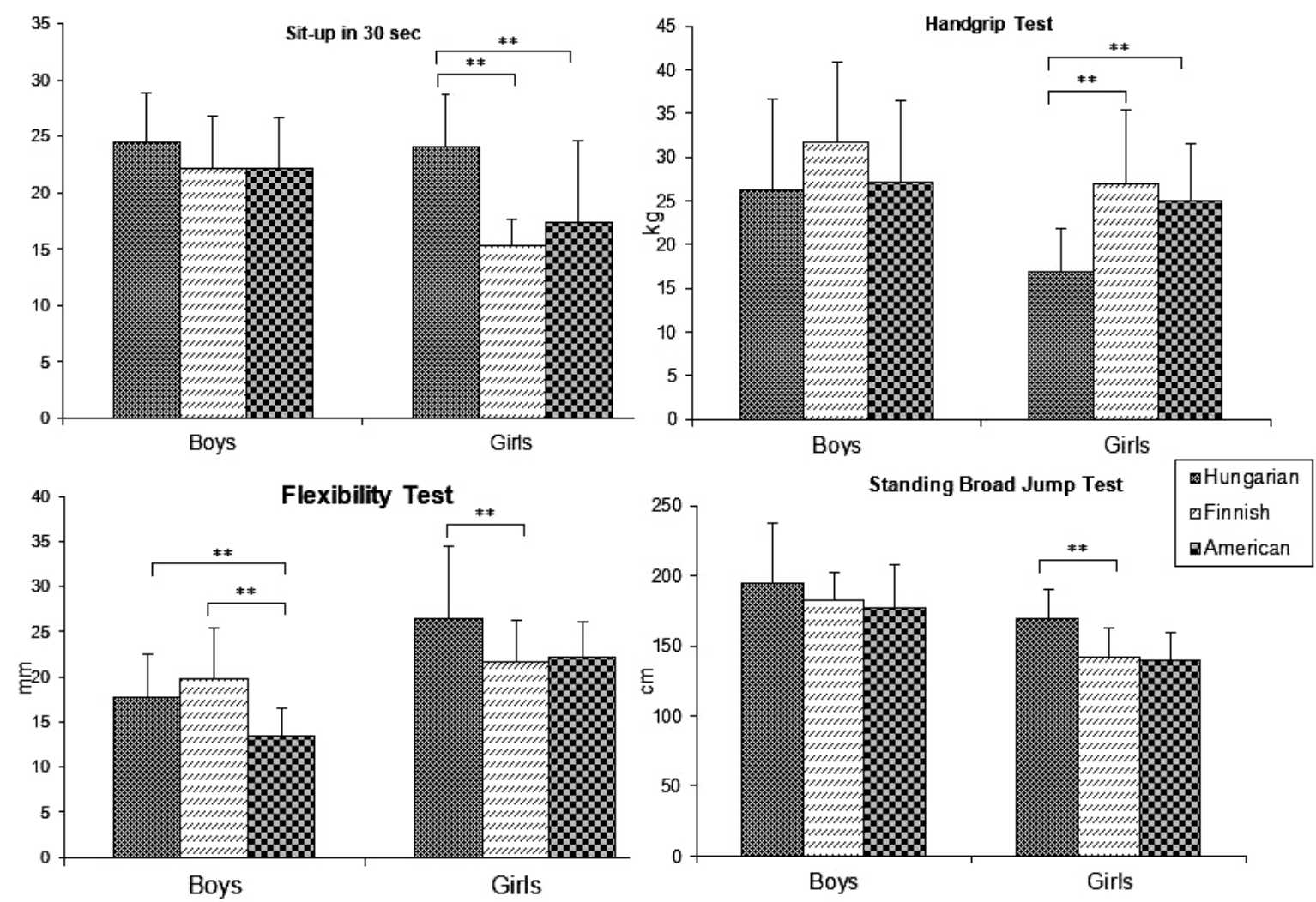

Figure 2. Significant differences (one-way ANOVA, see Table 2) in Eurofit tests of adolescents ages 10 to 14 according to ethnic identity.

Asterisks $\left({ }^{*} \mathrm{p}<0.05,{ }^{* *} \mathrm{p}<0.001\right)$ indicate results of post-hoc test (Bonferroni)

\section{Discussion}

In most part of the world the fitness of children and adolescents shows a decreasing trend while the prevalence of fatness is getting higher for at least 20 years (Vuorela, Saha \& Salo, 2011).

Our results show that there are many differences among the three studied groups. Interestingly enough Hungarian adolescents performed better in many tests than Finnish subjects, although standard deviations are really high in each measured groups. Hungarian pupils are the tallest in the studied population, but their BMI and body fat percentages are the lowest. Of the 123 adolescents $21.65 \%$ were found to be overweigth and $6.37 \%$ obese by the international BMI criteria. Obesity, 
however was defined based on BMI, which is an imperfect measure of body fat. It is not clear whether body fatness is a stronger predictor of obesity-related health outcomes or BMI (Freedman, Katzmarzyk, Dietz, Srinivasan, \& Berenson, 2009). BMI is highly correlated with the body fat at every level in this study. The prevalence of overweight and obesity in the Hungarian adolescents was $9.3 \%$, while 23.07\% in Finnish group and $38.2 \%$ among Americans. Ogden et al. reported that prevalence of obesity in the USA in 2009-2010 in children and adolescents was $16.9 \%$, that is much less than it was observed in our study (Ogden, Carroll, Kit, \& Flegal, 2012). This fact is mirrored in Conrad's MIX, since it is showing the ratio of muscle and fat in the body (Conrad, 1963). PLX is lower in the Hungarian group compared to the Finnish adolescents showing that in body composition the significant difference appears not only in bodyfat, but also in the skeletal and muscular components. These components are higher in the Finnish studied population. In the results of Handgrip test it also appears, while in standing broad jump, sit up, and bent arm hanging test Hungarians performed better. The positive consequences of every day regular physical activity appear in the $20 \mathrm{~m}$ shuttle run test. Finnish adolescents have a higher $\mathrm{VO}_{2} \mathrm{max}$ in both sexes, despite the fact that they are heavier, having more fat in their body than Hungarians.

Although around puberty changing body composition strongly alters/renders physical performance, the positive effect of regular daily exercise appears in different skills and abilities, but foremost in aerobic capacity. Aerobic capacity is the main limiting factor of physical performance not only in sport activities but in every day life also (Dumith, Van Dusen \& Kohl, 2012). However all WHO data and other studies show higher physical activity level and physical fitness in the Northern European countries or in US than in Hungary, in this study Hungarian adolescents show better performance in almost every motor tests. It is probably the consequence of the enhanced number of physical education lessons and possibilities for organized sport activities in the examined school, which is different from the average in Hungary.

In conclusion comparison between the different ethnic groups strongly suggests that adolescents need a higher amount and intensity of training in modern societies to achieve the proper physical activity level. Furthermore not only the level of physical activity, but also the quality of exercise determines the health status of adults. Limited flexibility of hamstring in adolescents might cause low-back pain in any age groups. Our results show a drawback in the sit and reach test. Proper programs for increasing flexibility in the classes would decrease the number of patients of low-back pain in modern societies (Rodriguez, Santonja, López-Minorro, Sáinz de Baranda, \& Yuste, 2008). Martín-Matillas and his colleges (2011) showed that encouragement of relatives and friends strongly correlates with physical activity level of adolescents highlighting the importance of communities in the health related fitness of generations.

\section{Acknowledgement}

The authors are grateful for the help and suggestions of Prof. Robert Gabriel. This work was supported by the Doctoral School of Health Sciences, the Erasmus Programme and the Faculty of Sciences of the University of Pécs.

\section{References}

Armstrong, N. \& Welsman, J. R. (2006). The physical activity patterns of European youth with reference to methods of assessment. Sports Medicine, 36,1067-1086. 
Boreham, C., Paliczka, P. J. \& Nichols, A. K. (1990). A comparison of PWC 170 and 20-MST tests of aerobic fitness in adolescent schoolchildren. The Journal of Sports Medicine and Physical Fitness, 30, 19-23.

Brook, C. G. D. (1971). Determination of body composition of children from skinfold measurements. Archives of Disease in Childhood, 46, 182-184.

Cole, T. J., Belizzi, M. C., Flegal, K. M. \& Dietz, W. H. (2000). Establishing a standard definition for child overweight and obesity worldwide: international survey. British Medical Journal, $320,1240-1243$.

Conrad, K. (1963). Der Konstitutiontypus. Springer - Verlag, Berlin

Currie, C., Hurrelmann, K., Settertobulte, W., Smith, R. \& Todd, J. (2000). Health and Health Behaviour Among Young People. Copenhagen: World Health Organisation.

Currie, C., Roberts, C., Morgan, A., Smith, R., Settertobulte, W., Samdal, O. \& Rasmussen, B. V. (2004). Young People's Health in Context. Copenhagen: World Health Organization.

Dumith, S. C., Van Dusen, D. \& Kohl, H. W. (2012). Physical fitness measures among children adolescents: are they all necessary? The Journal of Sports Medicine and Physical Fitness, $52,181-9$.

Durnin, J. V. \& Rahaman, M. M. (1967). The assessment of the amount of fat in the human body from measurements of skinfold thickness. British Journal of Nutrition, 21, 681-688.

Eurobarometer. Sport and physical activity; 2010. http://ec.europa.eu/public_opinion/archives/ ebs/ebs_334_en.pdf

EUROFIT European Tests of Physical Fitness. $2^{\text {nd }}$ Edition (1993). Council of Europe, Committee for Development of Sport. Sport Division Strasbourg, Council of Europe Publishing and Documentation Service: Strasbourg

Freedman, D. S., Katzmarzyk, P. T., Dietz, W. H., Srinivasan, S. R. \& Berenson, G. S. (2009). Relation of body mass index and skinfold thicknesses to cardiovascular disease risk factors in children: the Bogalusa Heart Study. The American Journal of Clinical Nutrition, 90, 210-6. doi:10.3945/ajcn.2009.27525. Epub 2009 May 6.

Ganley, K. J., Paterno, M. V., Miles, C., Stout, J., Brawner, L., Girolami, G. \& Warren, M. (2011). Health-related fitness in children and adolescents. Pediatric Physical Therapy, 23, 208-20.

Heath, B. H. \& Carter, J. E. L. (1967). A modified somatotype method. American Journal of Physical Anthropology,27, 57-74.

Kautiainen, S., Rimpelä, A., Vikat, A. \& Virtanen, S. M. (2002). Secular trends in overweight and obesity among Finnish adolescents in 1977-1999. International Journal of Obesity and Relatated Metabolic Disorders, 26, 544-52.

Malina, R. M. (2007). Physical fitness of children and adolescents in the United States: status and secular change. Medicine and Sport Science, 50, 67-90.

Marshall, S. J., Sarkin, J. A., Sallis, J. F. \& McKenzie, T. L. (1998). Tracking of health-related fitness components in youth ages 9 to 12. Medicine and Science in Sports and Exercise, 30, 910-916.

Martín-Matillas, M., Ortega, F. B., Ruiz, J.R., Martínez-Gómez, D., Marcos, A., Moliner Urdiales, D., Polito, A., . . \& \& Sjöström, M. (2011). HELENA study. Adolescent's physical activity levels and relatives' physical activity engagement and encouragement: the HELENA study. European Journal of Public Health, 21, 705-712. 
Maximova, K., O’Loughlin, J., Paradis, G., Hanley, J.A. \& Lynch, J. (2009). Declines in physical activity and higher systolic blood pressure in adolescence. American Journal of Epidemiology, 170, 1084-1094. doi:10.1093/aje/kwp255. Epub 2009 Sep 24.

McAlister, A., Puska, P., Stalonen, J.T., Tuomilehto, J. \& Koskela, K. (1982). Theory and action for health promotion illustrations from the North Karelia Project. American Journal of Public Health, 72, 43-50.

National Institute for Health Development (2003). National Health Program. Budapest: Author.

Nemet, D., Wang, P., Funahashi, T., Matsuzawa, Y., Tanaka, S., Engelman, L. \& Cooper, D. M. (2003). Adipocytokines, body composition, and fitness in children. Pediatric Research, 53, $148-152$.

Ogden, C. L., Carroll, M. D., Curtin, L. R., Lamb, M. M. \& Flegal, K. M. (2010). Prevalence of high body mass index in US children and adolescents, 2007-2008. The Journal of the American Medical Association, 303, 242-249.

Ogden, C. L., Carroll, M. D., Kit, B. K. \& Flegal, K. M. (2012). Prevalence of obesity and trend sin body mass index among US children and adolescents, 1999-2010. The Journal of the American Medical Association, 307, 483-490.

Photiou, A., Anning, J. H., Mészáros, J., Vajda, I., Mészáros, Z., Sziva, A., . . \& Ng, N. (2008). Lifestyle, Body Composition, and Physical Fitness Changes in Hungarian School Boys (1975-2005). Research Quarterly for Exercise and Sport, 79, 166-173.

Rodriguez, P. L., Santonja, F. M., López-Minorro, P. A., Sáinz de Baranda, P. \& Yuste, J. L. (2008). Effect of physical education stretching programme on sit-and-reach score in schoolchildren. Science and Sports, 23, 170-175.

Saar, M. (2008). The Relationships between anthropometry, physical activity and motor ability in 10-17-year-olds. PhD thesis. University of Tartu.

Sallis, J. \& Patrick, K. (1994). Physical activity guidelines for adolescents: consensus statement. Pediatric Exercise Science, 6, 302-314.

Santtila, M., Kyröläinen, H., Vasankari, T., Tiainen, S., Palvalin, K., Häkkinen, A. \& Häkkinen, K. (2006). Physical fitness profiles in young finnish men during the years 1975-2004. Medicine and Science in Sports and Exercise, 38, 1990-1994.

Slaughter, M. H., Lohman, T. G., Boileau, R. A., Horswill, C. A., Stillman, R. J., Van Loan, M. D. \& Bemben, D. A. (1988). Skinfold equations for estimation of body fatness in children and youth. Human Biology, 60, 709-23.

Tremblay, S. M., LeBlanc, G. A., Kho, E. M., Saunders, J. T., Larouche, R., Colley, C. R., . . . \& Gorber, C. S. (2011). Systematic review of sedentary behaviour and health indicators in school-aged children and youth. International Journal of Behavioral Nutrition and Physical Activity, 8, 98. doi:10.1186/1479-5868-8-98.

van Mechelen, W., Hlobil, H. \& Kemper, H. C. (1986). Validation of two running tests as estimates of maximal aerobic power in children. European Journal of Applied Physiology and Occupational Physiology, 55, 503-6.

Vuorela, N., Saha, M. T. \& Salo, M. K. (2011). Change in prevalence of overweight and obesity in Finnish children - comparison between 1974 and 2001. Acta Paediatrica, 100, 109-115.

World Health Statistics (2011). Geneva: World Health Organization. 